\title{
Hemorrhagic Complications Associated with the Use of Intravenous Tissue Plasminogen Activator in Treatment of Acute Myocardial Infarction
}

\author{
RoBert M. CALIFF, M.D. Durham, North Carolina ERIC J. TOPOL, M.D. Ann Arbor, Michigan BARRY S. \\ GEORGE, M.D. Columbus, Ohio JANE M. BoswiCK, M.P.H. Durham, North Carolina CHARLES ABBotTSMITH, \\ M.D. Cincinnati, Ohio KRISTINA N. SIGMON, M.A. Durham, North Carolina RICHARD CANDELA, M.D., RamONA \\ MASEK, R.N. Columbus, Ohio DEAN KEREIAKES, M.D.Cincinnati, Ohio WILLIAM W. O'NEILL, M.D. Ann Arbor, \\ Michigan RICHARD S. STACK, M.D. Durham, North Carolina DAVID STUMP, M.D. Burlington, Vermont and the \\ Thrombolysis and Angioplasty in Myocardial Infarction Study Group
}

PURPOSE: Little attention has been paid to the importance of clinical factors associated with bleeding complications caused by the use of thrombolytic agents. The goal of our study was to examine clinical and hematologic factors associated with an increased risk of bleeding in a prospectively observed population that received intravenous tissue plasminogen activator for acute myocardial infarction.

PATIENTS AND METHODS: Bleeding complications were evaluated in 386 consecutive patients treated with $150 \mathrm{mg}$ of tissue plasminogen activator over six to eight hours for acute myocardial infarction. All patients also underwent immediate cardiac catheterization.

RESULTS: Quantitation of blood loss during the patients' hospital stay included a median drop in hematocrit of 11.4 points, a median nadir hematocrit of 31.2, a 14 percent rate of significant clinically evident bleeding, and a 31 percent rate of transfusion of two or more units of blood. All of these parameters were much more severe in patients treated with coronary artery bypass surgery. Access site hematoma was the most common source of bleeding ( 45 percent of patients), whereas 8 percent had gastrointestinal bleeding, two patients had retroperitoneal bleeding, and two patients had intracranial bleeding. The median nadir fibrinogen was $1.3 \mathrm{~g} /$ liter. Multiple linear regression models were used to investigate the relationship between clinical variables, including multiple hematologic measurements, and measures of the amount of blood loss. The use of coronary artery bypass grafting was the variable most closely associated with hemorrhage. Other invasive procedures (angioplasty and intra-aortic balloon pumping) were also associated with increased bleeding. Among the patient descriptors examined, lighter weight, older age, female sex, and history of hypertension were associated with greater blood loss. Of laboratory coagulation parameters, only nadir fibrinogen levels were significantly associated with more bleeding.

CONCLUSION: Careful clinical evaluation may improve assessment of the risk/benefit ratio of thrombolytic therapy.
$\mathbf{T}$ he advent of drugs with relative fibrin specificity raised hopes that coronary thrombi could be lysed without disturbing the systemic coagulation system [1-3]. For this reason, the major impetus to the development of new thrombolytic agents has been the search for compounds with greater fibrin specificity. Older thrombolytic agents, such as streptokinase and urokinase, were known to be associated with significant bleeding complication rates $[4,5]$, at least in part due to the systemic lytic state induced by the depletion of fibrinogen in the systemic circulation [6,7]. Early studies with the prototype fibrin-specific agent, tissue plasminogen activator (t-PA), suggested that although some systemic fibrinogen breakdown occurred, relative sparing of fibrinogen with a low bleeding complication rate was observed [8-10].

While attention has focused on the hematologic parameters associated with bleeding, few studies have examined the importance of clinical factors [11]. Older age has been associated with an increased risk of bleeding complications with streptokinase use in one study, but this finding has not been replicated because no other studies have evaluated this factor [12]. Although fibrinogen is the most commonly discussed measure of the systemic effects of t-PA, other hematologic factors that can be measured might also affect the risk of bleeding. Fibrin(ogen) degradation products are products of fibrinolysis that possess potent anticoagulant and antiplatelet effects. The plasma level of t-PA achieved in the blood can now also be estimated by accurate and precise assays. The goal of this study was to examine clinical and hematologic factors associated with an increased risk of bleeding in a prospectively observed population treated with intravenous t-PA for acute myocardial infarction.

\section{PATIENTS AND METHODS}

Patient Population

A detailed accounting of the patients enrolled in this trial has been reported previously $[13,14]$. Briefly, pa-

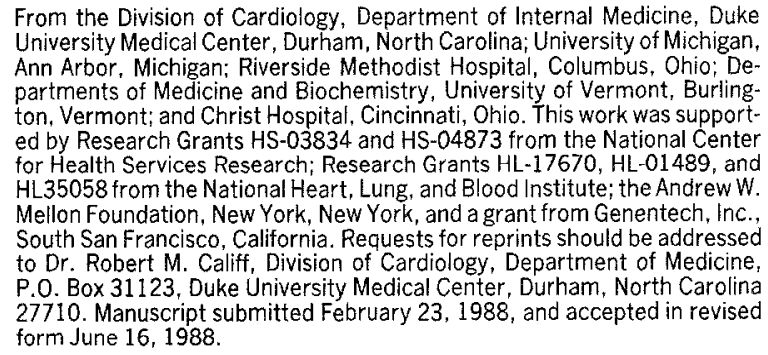




\section{TABLE I}

\section{Characteristics of population}

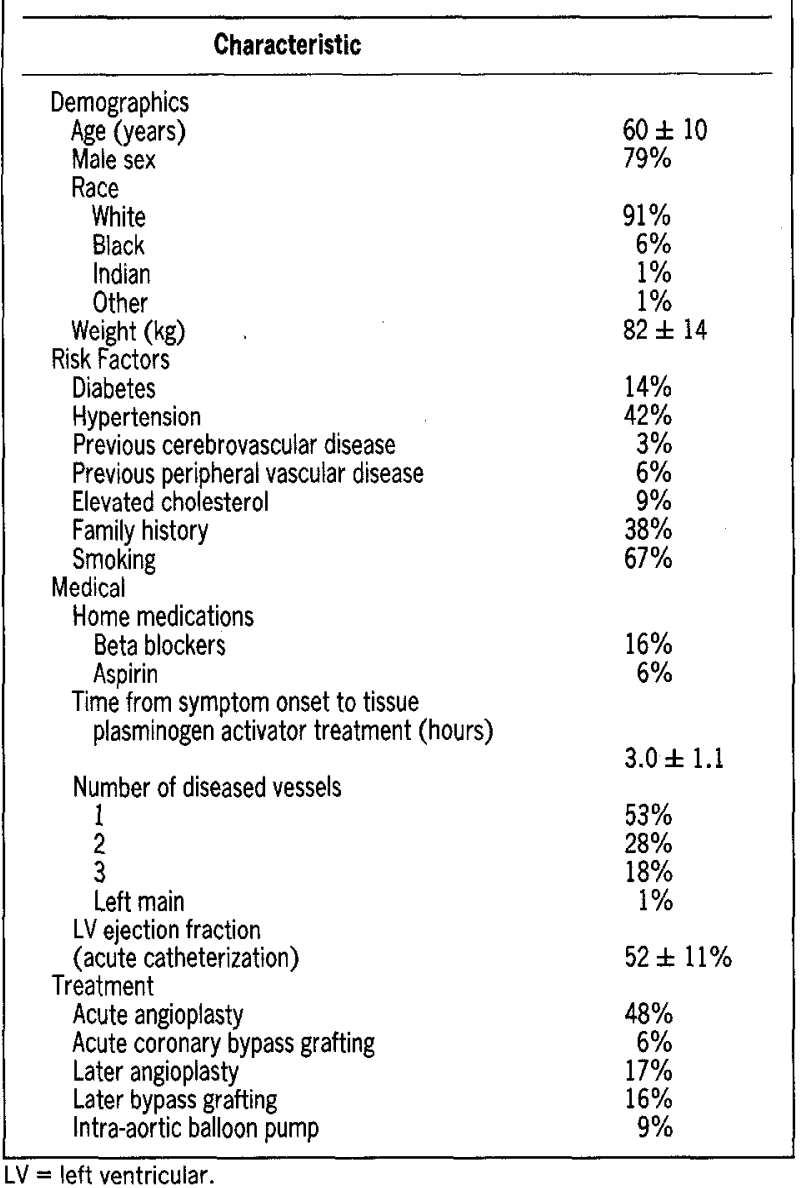

tients with symptoms of acute myocardial infarction of 30 minutes to six hours were included if they had ST-segment elevation of at least $0.1 \mathrm{mV}$ in at least two contiguous leads of the standard 12-lead electrocardiogram. The usual contraindications to thrombolytic therapy, including history or risk factors for serious hemorrhage, were observed. Specifically, the following factors were considered to be contraindications to entry into the protocol: recent (less than six months) trauma, major surgery within two weeks, recent active internal bleeding (gastrointestinal or genitourinary), structural brain disease including tumor or arteriovenous malformation, uncontrolled hypertension (diastolic blood pressure greater than $120 \mathrm{~mm} \mathrm{Hg}$ by several measurements), other serious advanced illnesses such as cancer, or prolonged cardiopulmonary resuscitation within two weeks. Patients with a history of stroke within six months were excluded, although those with a more distant stroke were included in the trial. Additionally, patients with age over 75 years, previous coronary artery bypass surgery, or cardiogenic shock on presentation were excluded. A total of 386 patients were enrolled in the trial from five centers. Table I displays the baseline characteristics of the entire population.

\section{t-PA Administration}

All patients were treated with an infusion of predominantly single-chain t-PA begun as rapidly as pos- sible after informed consent was obtained. In the first 176 patients, $60 \mathrm{mg}$ was given intravenously over the first hour, followed by $20 \mathrm{mg} /$ hour for two hours and 10 $\mathrm{mg} /$ hour over the next five hours. Because of evidence from other studies that a weight-adjusted dose might be more effective, in the last 210 patients a dose of 1 $\mathrm{mg} / \mathrm{kg}$ was given over the first hour, with a maximum dose of $90 \mathrm{mg}$, followed by the remainder of a total dose of $150 \mathrm{mg}$ over the next five hours. The clinical results of the two dose regimens have been reported previously [15]. The weight-adjusted dose was associated with less bleeding, whereas patency rates were similar with the two regimens. A bolus of 10 percent of the first-hour dose was given throughout the study.

\section{Interventional Strategy}

All patients underwent coronary angiography and left ventriculography at 90 minutes after initiation of t-PA therapy. Based on the results of this procedure, each patient was assigned to one of several groups. If the infarct vessel was totally occluded at 90 minutes with a significant amount of myocardium remaining in jeopardy, immediate angioplasty was attempted. Patients with patent infarct vessels and TIMI (Thrombolysis in Myocardial Infarction) grade 2 or 3 flow were assessed in the interventional cardiac catheterization laboratory for suitability for angioplasty. Those who were not suitable underwent triage to the Cardiac Care Unit for further pharmacologic therapy. In addition, patients in whom cardiogenic shock developed after enrollment in the trial were treated with angioplasty or surgery at the discretion of the investigator. Those with ambiguous delineation of the infarct artery or less than 50 percent residual stenosis on the 90-minute angiogram did not undergo immediate angioplasty. Patients whose infarct arteries were patent and suitable for angioplasty were randomly assigned to receive either immediate angioplasty or delayed angioplasty one week later if clinically indicated or soon$\mathrm{er}$ if required because of the occurrence of clinically significant ischemia.

All patients were treated with a standardized medical regimen after leaving the interventional catheterization laboratory. Heparin was maintained by continuous infusion for a minimum of 24 hours to keep the activated partial thromboplastin time 1.5 to 2.0 times baseline. In patients with residual stenosis greater than 50 percent or with a large intimal dissection after angioplasty, the heparin was maintained until a final decision about further intervention was made (usually one week). Aspirin was started either just after treatment was initiated or just after cardiac catheterization. Aspirin $325 \mathrm{mg} /$ day and dipyridamole $75 \mathrm{mg}$ three times per day were continued throughout the hospitalization. Diltiazem was given in a dose of 30 to $90 \mathrm{mg}$ four times per day unless contraindicated. Because of concern about confounding effects on left ventricular function, beta blockers were withheld unless a strong indication (hypertension, angina, or arrhythmia) necessitated their use. Lidocaine was given intravenously for 24 hours as prophylaxis against ventricular arrhythmias.

Monitoring included frequent measurement of the prothrombin time and activated partial thromboplastin time (minimum of once daily for the first three days). In addition, the hematocrit was measured at least once daily for the first three days of treatment 
and additionally concomitantly with the occurrence of a clinical event.

Severe, recurrent ischemia was defined prospectively as 20 minutes of ischemic symptoms associated with new electrocardiographic ST-segment changes unresponsive to standard nitroglycerin therapy. Patients meeting these criteria returned to the cardiac catheterization laboratory, where coronary angiography was repeated and angioplasty or coronary artery bypass grafting was performed as clinically indicated. Retreatment with t-PA was not used.

\section{Measurement of Hematologic Variables}

T-PA antigen, fibrinogen, and fibrin(ogen) degradation products were measured at baseline, three, five, eight, and 12 hours after initiation of t-PA therapy. Samples were collected in $0.01 \mathrm{M}$ citrate and $1 \mu \mathrm{M}$ of de-Phe-Pro-Arg-Chloromethylketone as previously described to avoid in vitro assay artifacts [16]. The blood was immediately placed on ice, centrifuged cellfree within one hour, and the plasma was stored frozen. At the time of first thawing, functional assays were performed and serum was prepared for fibrin(ogen) degradation product assays. Quantitation of t-PA antigen by immunoassay was performed after one additional thawing. The fibrinogen levels were measured by both the functional method of Clauss [17] and by sulphite precipitation as modified by Vermylen et al [18]. Fibrin(ogen) degradation products were measured with a hemagglutination inhibition immunoassay [19]. For the measurement of fibrin(ogen) degradation products, plasma was mixed with an equal volume of thrombin and aprotinin for two hours at $37^{\circ} \mathrm{C}$. An enzyme-linked immunosorbent assay based on three monoclonal antibodies was used to measure $t$ PA antigen [20]. Plasminogen activator inhibitor activity was measured in baseline samples only via $15-$ minute neutralization of exogenously added $t-P A$ as described by Verheijen and co-workers [21].

\section{Assessment of Bleeding Complications}

Clinical research nurses evaluated the patients on a daily basis for overt evidence of bleeding. Emesis and stool were checked for the presence of occult blood. Serial hematocrits during the hospitalization and at the time of discharge were recorded prospectively. After hospital discharge, all charts were reviewed for previously unreported episodes of bleeding, and the amount of blood products used was tabulated. An estimate of the net blood loss was calculated by adding the number of transfused units of packed red blood cells and the admission minus nadir hematocrit divided by three [22].

Specific sites of bleeding were quantified in the following manner. Intracranial bleeding was recorded when a new neurologic deficit occurred and a cranial axial tomographic scan revealed evidence of blood density. All patients in the study with new neurologic deficits underwent cranial axial tomographic scanning. The presence of gross blood or a guaiac-positive test result in emesis or stool was recorded as gastrointestinal bleeding. A collection of blood in the retroperitoneal space documented by computed tomography or surgical exploration was classified as retroperitoneal bleeding.

Bleeding rates were also tabulated using a classification scheme developed in the TIMI trial [23,24]. In this system, a drop in hematocrit greater than 15

\begin{tabular}{|l|}
\hline TABLE II \\
Candidate Variables \\
\hline Demographic \\
Age \\
Sex \\
Weight \\
\hline Baseline \\
Hypertension \\
Diabetes \\
Peripheral vascular disease \\
Cerebrovascular disease \\
\hline Angiographic \\
Patency at 90 minutes \\
Reocclusion \\
\hline Treatment \\
Surgery \\
Angioplasty (acute or delayed) \\
Intra-aortic balloon pumping \\
\hline Hematologic \\
Nadir fibrinogen \\
Clauss method \\
Sulphite method \\
Peak t-PA antigen \\
Peak fibrin degradation products \\
PA inhibitor level \\
\hline Treatment location \\
Center \\
\hline PA = plasminogen activator. \\
\hline
\end{tabular}

points is considered "major," whereas a drop of 10 to 15 points is considered "minor." In addition, gross hematuria or hematemesis with a drop in hematocrit less than 10 points is considered "minor" bleeding.

\section{Statistical Methods}

The overall amount of bleeding was reported for the entire population and for those patients not undergoing surgery by tabulating the median, 25 th, and 75 th percentiles of nadir and change from baseline to nadir $(\Delta)$ hematocrit. Similar statistics were reported for blood products used. Cumulative episodes of clinically evident bleeding were listed by site, and rates of significant bleeding according to the TIMI criteria were tabulated.

Since no single measure completely captures the amount of blood loss, multiple linear regression models were developed to examine the relationships among clinical baseline characteristics, hematologic measurements before and during therapy, interventional treatment beyond thrombolytic therapy, and measures of bleeding. 'The candidate independent variables tested in the models are listed in Table II. Measures of bleeding included requirement for two units of blood transfusion, nadir hematocrit, $\Delta$ hematocrit, and clinically evident episodes of bleeding. The results of these models then were compared to establish consistent trends among factors associated with different measures of bleeding. Because of the exploratory nature of the analyses, an alpha level of less than 0.10 was used to include a variable in each of the final models.

To demonstrate the relationship between significant variables in the models and clinical outcomes, median, 25th, and 75th percentile levels as well as means and standard deviations for estimated units of blood loss were reported for each level of binary pre- 


\section{TABLE III}

Bleeding Parameters*

\begin{tabular}{|ccc|}
\hline & $\begin{array}{c}\text { All Patients } \\
(\mathbf{n}=386)\end{array}$ & $\begin{array}{c}\text { Non-Operated } \\
\text { Patients } \\
(\mathbf{n}=\mathbf{3 0 2})\end{array}$ \\
\hline Nadir hematocrit & $31.2(27.8-35.3)$ & $32.6(28.9-36.2)$ \\
$\Delta$ hematocrit & $-11.4(-15.4$ to -8.0$)$ & $-10.6(-14.3$ to -7.4$)$ \\
Units lost & $4(3-7)$ & $4(3-5)$ \\
Units transfused & $0(0-2)$ & $0(0-2)$ \\
& Mean $=1.76$ & Mean $=0.84$ \\
\hline
\end{tabular}

* Entries are median (25th to 75th percentile)

+ Units transfused $+\Delta$ hematocrit $/ 3$.

\section{TABLE IV}

\section{Bleeding Manifestations}

\begin{tabular}{lcc}
\hline & \multicolumn{2}{c}{ Number (percent) } \\
\cline { 2 - 3 } & $\begin{array}{c}\text { All Patients } \\
(\mathbf{n}=\mathbf{3 8 6})\end{array}$ & $\begin{array}{c}\text { Non-Operated } \\
\text { Patients } \\
(\mathbf{n}=302)\end{array}$ \\
\hline "Major" bleed & & \\
TAMl criteria & $55(14)$ & $31(10)$ \\
TIMl criteria & $89(23)$ & $48(16)$ \\
"Minor" bleed & & \\
TIMI Criteria & $93(24)$ & $70(23)$ \\
Transfusion $\geq 2$ units & $120(31)$ & $64(21)$ \\
Groin hematoma & $174(45)$ & $143(47)$ \\
Gastrointestinal bleed & $30(8)$ & $26(9)$ \\
"Stroke & $6(2)$ & $4(1)$ \\
Intracranial bleed & $2(0.5)$ & $2(0.7)$ \\
Vascular repair & $15(4)$ & $11(4)$ \\
Retroperitoneal bleed & $2(0.5)$ & $2(0.7)$ \\
\hline
\end{tabular}

* All patients with stroke were evaluated by computerized tomography for evidence of intracranial bleed.

\section{TABLE V}

Hematologic Values*

\begin{tabular}{|c|c|c|}
\hline & Value & $\begin{array}{c}\text { Normal } \\
\text { Range }\end{array}$ \\
\hline \multicolumn{3}{|l|}{ Nadir fibrinogen } \\
\hline Clauss method (g/liter) & $1.30(0.72-1.70)$ & $1.5-3.0$ \\
\hline Sulphite method (g/liter) & $1.50(1.00-2.02)$ & $1.5-3.0$ \\
\hline $\begin{array}{l}\text { Peak fibrinogen degradation } \\
\text { products }(\mu \mathrm{g} / \mathrm{ml})\end{array}$ & $60(15-210)$ & $<2$ \\
\hline $\begin{array}{l}\text { Baseline plasminogen activator } \\
\text { inhibitor }(\mathrm{IU} / \mathrm{ml})\end{array}$ & $12(7-20)$ & $<5$ \\
\hline Peak t-PA antigen $(\mathrm{ng} / \mathrm{ml})$ & $1,430(900-2,920)$ & $5-20$ \\
\hline
\end{tabular}

dictor variables. Scatter plots showing the average number of units lost by deciles of the predictor variable were used to illustrate these relationships for continuous variables.

\section{RESULTS}

As shown in Tables III and IV, bleeding events were frequent in the entire population. The median drop in hematocrit was 11.4 points with an interquartile range of -15.4 to -8.0 points. Blood transfusion was required in 34 percent of patients, and 31 percent required at least two units of packed red blood cell transfusions (Table III). Clinically evident bleeding was less frequent, observed in 14.2 percent of patients (Table IV). When the TIMI classification was applied,

\section{TABLE V}

Linear Regression Model Results

\begin{tabular}{|c|c|c|c|}
\hline $\begin{array}{l}\text { Dependent } \\
\text { Variable }\end{array}$ & $\begin{array}{c}\text { Independent } \\
\text { Variables }\end{array}$ & $\begin{array}{l}\text { Regression } \\
\text { Coefficient }\end{array}$ & p Value \\
\hline \multicolumn{4}{|l|}{ "Major bleed" } \\
\hline & $\begin{array}{l}\text { Weight } \\
\text { PA Inhibitor }\end{array}$ & $\begin{array}{r}-0.029 \\
0.016\end{array}$ & $\begin{array}{l}0.024 \\
0.030\end{array}$ \\
\hline \multicolumn{4}{|l|}{$\Delta$ hematocrit } \\
\hline & $\begin{array}{l}\text { Female gender } \\
\text { Hypertension } \\
\text { Acute PTCA } \\
\text { Late PTCA } \\
\text { IABP } \\
\text { PA Inhibitor }\end{array}$ & $\begin{array}{r}1.52 \\
-1.63 \\
2.26 \\
1.79 \\
3.25 \\
0.03\end{array}$ & $\begin{array}{l}0.069 \\
0.019 \\
0.003 \\
0.056 \\
0.051 \\
0.053\end{array}$ \\
\hline \multicolumn{4}{|l|}{ Nadir hematocrit } \\
\hline & $\begin{array}{l}\text { Age } \\
\text { Female gender } \\
\text { IABP } \\
\text { Weight } \\
\text { Center } 2 \\
\text { Nadir fibrinogen }\end{array}$ & $\begin{array}{r}-0.13 \\
-2.59 \\
-3.14 \\
-0.06 \\
-1.49 \\
0.78\end{array}$ & $\begin{array}{l}0.0001 \\
0.002 \\
0.036 \\
0.007 \\
0.026 \\
0.084\end{array}$ \\
\hline \multicolumn{4}{|l|}{$\begin{array}{l}\text { Units transfused } \\
+\Delta \text { hematocrit } / 3\end{array}$} \\
\hline & $\begin{array}{l}\text { Age } \\
\text { Female gender } \\
\text { Hypertension } \\
\text { Acute PTCA } \\
\text { IABP } \\
\text { Nadir fibrinogen } \\
\text { PA inhibitor }\end{array}$ & $\begin{array}{r}0.03 \\
1.28 \\
-0.72 \\
0.97 \\
4.51 \\
-0.86 \\
0.02\end{array}$ & $\begin{array}{l}0.095 \\
0.012 \\
0.091 \\
0.019 \\
0.0001 \\
0.005 \\
0.099\end{array}$ \\
\hline
\end{tabular}

$\mathrm{PA}=$ plasminogen activator: $\mathrm{PTCA}=$ percutaneous transluminal coronary angioplasty; $\mid \mathrm{ABP}=$ intra-aortic balloon pump; $\Delta=$ change from baseline to pre-discharge value.

\begin{tabular}{|c|c|c|}
\hline \multicolumn{3}{|c|}{$\begin{array}{l}\text { TABLE VII } \\
\text { Profile of Two Patients with Intracranial Bleeding }\end{array}$} \\
\hline & Patient 1 & Patient 2 \\
\hline $\begin{array}{l}\text { Age } \\
\text { Sex } \\
\text { Weight }(\mathrm{kg}) \\
\text { Hypertension }\end{array}$ & $\begin{array}{l}63 \\
\text { Female } \\
75 \\
\text { Yes }\end{array}$ & $\begin{array}{l}74 \\
\text { Female } \\
68 \\
\text { No }\end{array}$ \\
\hline $\begin{array}{l}\text { Fibrinogen (Cla } \\
\text { Baseline } \\
3 \text { hours } \\
5-8 \text { hours }\end{array}$ & $\begin{array}{l}5.0 \\
0.48 \\
0.71\end{array}$ & $\begin{array}{l}4.0 \\
0.72 \\
0.60\end{array}$ \\
\hline $\begin{array}{l}\text { Fibrin (ogen) } \\
\text { Baseline } \\
3 \text { hours } \\
5-8 \text { hours }\end{array}$ & $\begin{array}{c}(\mathrm{g} / \mathrm{ml}) \\
5 \\
770 \\
400\end{array}$ & $\begin{array}{r}5 \\
400 \\
770\end{array}$ \\
\hline
\end{tabular}

23 percent of patients had "major" bleeding episodes and 24 percent of patients had "minor" bleeding. When the 23 percent of patients enrolled in the trial who underwent coronary artery bypass grafting were removed from the analysis, the amount of blood loss was less profound: 16 percent of patients had "major" bleeding and 23 percent had "minor" bleeding.

Table V demonstrates the changes in basic hematologic parameters in the entire population. A significant depletion of fibrinogen occurred in the majority of patients, with 25 percent of patients experiencing a drop to a nadir fibrinogen less than $0.7 \mathrm{~g} /$ liter (normal value: 1.5 to $3.0 \mathrm{~g} /$ liter). This decline in fibrinogen was accompanied by an elevation in fibrin(ogen) degradation products. Baseline plasminogen activator inhibi- 
tor levels were $12 \mathrm{IU} / \mathrm{ml}$, and peak t-PA antigen levels rose to $1,430 \mathrm{ng} / \mathrm{ml}$.

Table VI demonstrates the results of the linear regression models relating the clinical and treatment variables to the bleeding parameters. The influence of bypass surgery was so strong that patients treated with this procedure were excluded from the models. Although some inconsistency between models was observed, the factors that were most commonly associated with increased bleeding risk were invasive procedures (angioplasty and intra-aortic balloon pumping), female sex, smaller size, and older age. These factors pertain to both dose groups. Early or previous use of aspirin had no discernable effect on bleeding complications. The hematologic measurements that were related to increased bleeding risk in several of the models were the level of fibrinogen depletion measured with the Clauss [17] method and the plasminogen activator inhibitor levels (at baseline). When surgical patients were included in the analysis, the importance of the clinical variables remained relatively constant.

Table VII demonstrates the clinical and fibrinolytic profile of the two patients with intracranial bleeding in the trial. One of the patients died in-hospital of complications arising from the debilitation caused by the stroke. The second patient survived the hospitalization.

Figure 1 demonstrates the relationship between baseline patient weight and the estimated number of units of blood loss. Lighter patients were at highest risk of bleeding. Figure 2 graphically demonstrates the relationship between nadir fibrinogen by the Clauss [17] method and the summary measure of blood loss. Patients with substantial fibrinogen depletion had a greater amount of blood loss during the hospitalization. Figure 3 displays the relationship between age and estimated blood loss, demonstrating greater blood loss in older patients.

Figure 4 demonstrates the relationship between binary clinical variables and blood loss. Patients who underwent surgery, intra-aortic balloon pumping, or acute angioplasty had greater blood loss compared with patients who did not undergo these procedures. Furthermore, patients with a history of hypertension and women had a higher risk of bleeding.

\section{COMMENTS}

The major finding of this study is that evaluation of clinical and hematologic factors can lead to improved ability to assess the risk of significant hemorrhage in patients during treatment with t-PA. The careful accumulation of a large data base in a multicenter trial has allowed an in-depth examination of this large, heterogeneous population. Confirmation of these results in future studies could lead to a re-evaluation of the risk/benefit ratio for specific patient subgroups or to adjustment of the recommended dosage of thrombolytic drugs. Whether these relationships are common to treatment with all thrombolytic agents or unique to $\mathrm{t}-\mathrm{PA}$ remains a matter of speculation.

The initial enthusiasm that t-PA therapy would be associated with little clinical hemorrhage because of its fibrin specificity has proven to be unfounded. Comparison of t-PA and streptokinase in the TIMI trial $[11,23]$ failed to demonstrate a major advantage of either with respect to bleeding complications despite less fibrinogen depletion and fibrin(ogen) degradation

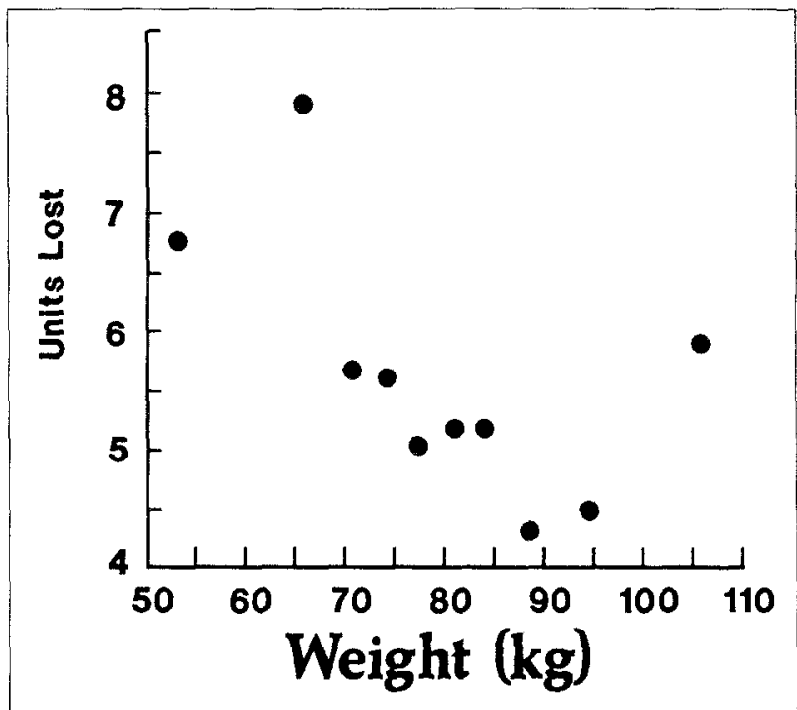

Figure 1. Estimated blood loss (number of units transfused plus $\Delta$ hematocrit/3) according to deciles of weight.

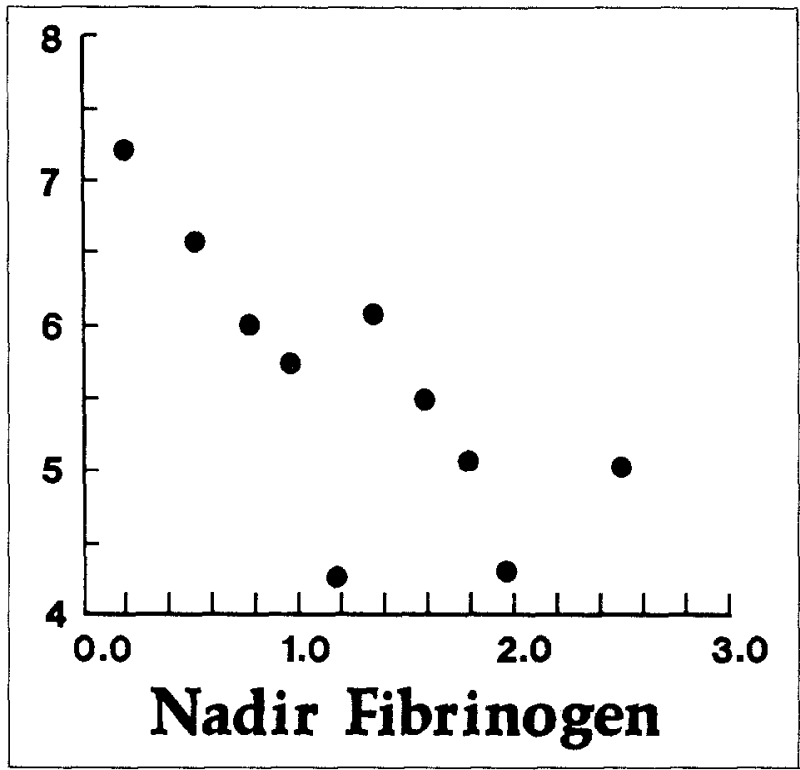

Figure 2. Estimated blood loss (number of units transfused plus $\Delta$ hematocrit/3) according to deciles of nadir fibrinogen.

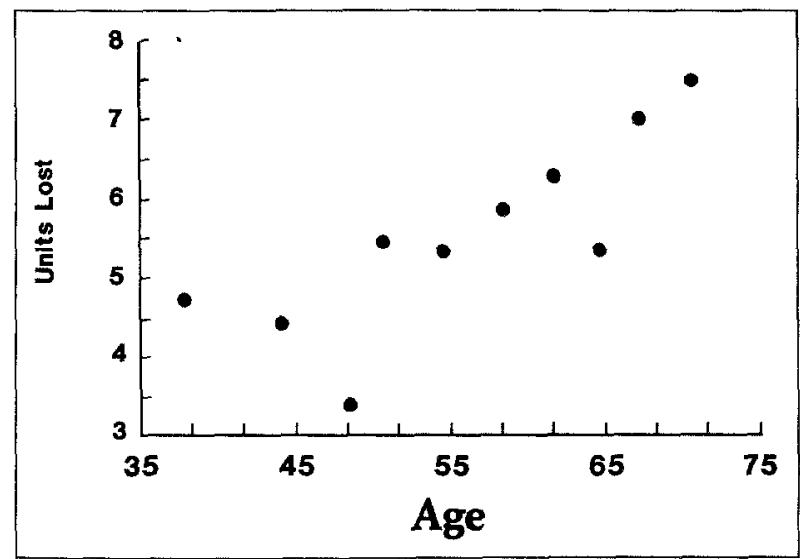

Figure 3. Estimated blood loss (number of units transfused plus $\Delta$ hematocrit/3) according to deciles of patient age. 


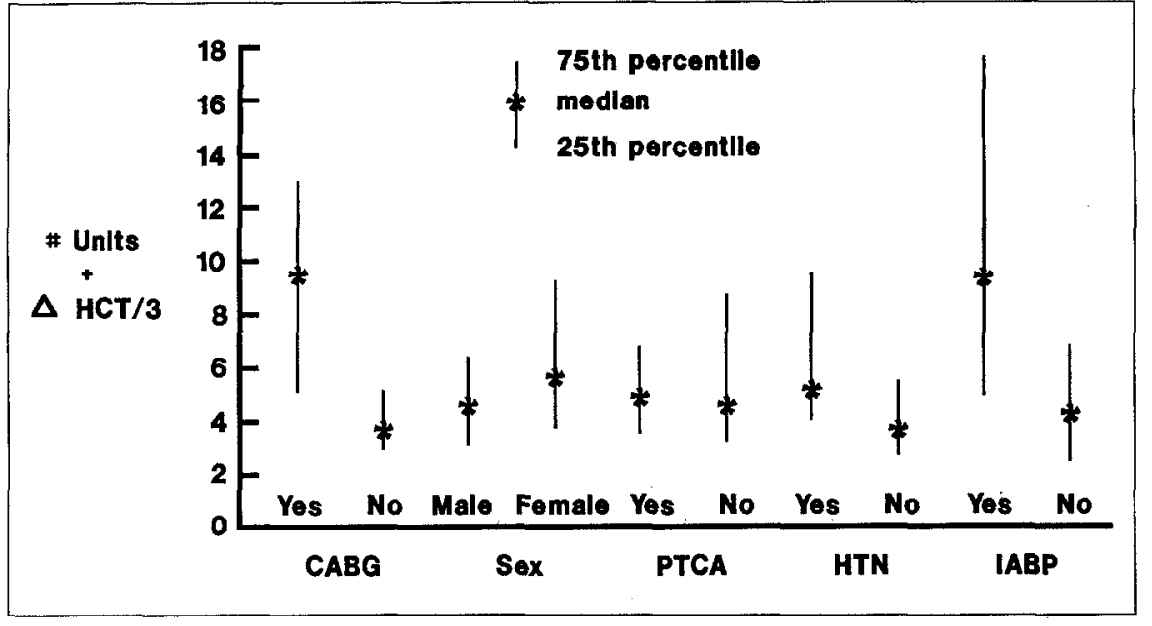

Figure 4. Estimated blood loss (number of units transfused plus $\Delta$ hematocrit/ 3 ) according to selected patient variables. ${ }^{*}=$ median; $I=$ interquartile range. $\mathrm{Hct}=$ hematocrit; $\mathrm{CABG}=$ coronary artery bypass graft; $\mathrm{PTCA}=$ percutaneous transluminal coronary angioplasty; $\mathrm{HTN}=$ hypertension; $\mathrm{IABP}=$ intra-aortic balloon pump. product accumulation in t-PA-treated patients. The European Cooperative Study showed only minor differences in favor of t-PA [25]. The higher than anticipated bleeding complication rates observed after $t-P A$ therapy could be attributed to multiple factors. In contrast to the early trials using t-PA, the higher doses of t-PA in this trial resulted in significant fibrinogen depletion. In addition, the use of continuous intravenous heparin, aspirin, and dipyridamole therapy may have enhanced the bleeding risk. Finally, as reflected by the results of the various models, the frequent use of invasive procedures produced multiple vascular hemostatic plugs that were susceptible to lysis by the fibrinolytic action of t-PA.

The amount of bleeding recorded in this trial is comparable to reports of more recent trials using t-PA and other thrombolytic agents when immediate cardiac catheterization was performed. The TIMI I trial reported a 43 to 47 percent incidence of periaccess hematoma and a 22 percent requirement for transfusion when transfusions related to procedures (surgery or percutaneous transluminal coronary angioplasty) or other diseases were excluded. When all patients were included, 29 percent of patients required transfusions [24]. The recent TIMI IA report found that the amount of bleeding after t-PA therapy was dose related, but that substantial transfusion rates occurred, even when the total dose of t-PA was restricted to 100 mg [24]. The European Cooperative Study comparing streptokinase with t-PA also noted similar bleeding complication rates [25]. Large European trials such as GISSI [26] and ISAM [27] did not employ early cardiac catheterization, and thus the degrees of bleeding complications are not strictly comparable. Nevertheless, examination of these data confirms that avoiding early catheterization substantially reduces bleeding risk.

Previous trials have not examined the specific clinical factors associated with increased risk of hemorrhage in a large population of patients. The finding of increased risk with invasive procedures is not surprising, since agents with the ability to lyse a coronary thrombus would be expected to produce concomitant lysis of vascular hemostatic plugs. This increased risk of bleeding with invasive procedures must therefore be weighed against the possible benefits of such procedures both in preventing recurrent ischemia [28,29] and in mechanically restoring coronary blood flow when thrombolytic therapy fails [30,31]. Importantly for the performance of invasive procedures soon after thrombolytic therapy, 4 percent of patients required a direct repair of the artery. Although this complication necessitated an expert vascular surgeon, in no case in this trial did permanent disability or loss of limb occur as a result of an access site vascular complication.

Clinical factors should be considered when decisions are made about the dose and risk/benefit ratio of thrombolytic therapy administration. One previous study has found an increased risk of bleeding in elderly patients treated with intravenous streptokinase [11]. Other clinical factors considered in this study have not been specifically evaluated in previous studies. The higher risk of bleeding in women and in lighter patients may reflect a need to adjust dose according to sex and body weight [15]. However, confirmatory studies are needed before definitive therapeutic recommendations can be made.

A major problem with studies of bleeding complications in the clinical environment is that the amount of blood loss and the consequences to the patient can be difficult to document. The number of transfusions received by the patient is confounded by the differing thresholds for transfusion among clinicians and institutions. Interpretation of the importance of nadir hematocrit or the change in hematocrit from admission to nadir is confounded by the variable frequency of sampling and the amount of transfusion. In order to compensate for these problems, Landefeld et al [22] have proposed the use of a summary measure as used in the current study in order to synthesize estimates of both blood loss and replacement. The TIMI trial used a similar adjustment [11]. Objective evidence of the amount of blood loss at puncture sites is extremely difficult to collect from evaluation of access site hematomas, because a large amount of blood loss may occur in the retroperitoneal space. In addition, widely variable thigh girth among patients can lead to inability to accurately visualize the blood that is present. Despite these problems, bleeding remains the major risk of thrombolytic therapy, and attempts to better quantify this risk in a manner that can be used across different studies are mandatory.

The most serious bleeding complication of thrombolytic therapy, which frequently results in death or permanent disability, is intracranial bleeding. Both patients with this complication in the current study conform in some ways to previous reports of high-risk patients [32]. Although neither patient had a history 
or clinical findings compatible with previous stroke or structural cerebrovascular disease, both were women, one was 63 years old with a history of hypertension, and the other was 74 years old. Both patients had marked fibrinogen depletion and a large accumulation of fibrin degradation products. Additional studies with careful evaluation of patients with intracranial bleeding are needed to delineate more specifically patients in whom thrombolytic therapy should be contraindicated.

These findings must be tempered by the reduction in the recommended dosage of $t-P A$ that has occurred since this trial was completed. Because of concern that higher doses caused increased bleeding complications, and no substantial increase in efficacy, the recommended dose of $t-P A$ was reduced from $150 \mathrm{mg}$ to 100 mg. Concern about intracranial hemorrhage rates with the higher doses of t-PA were paramount in this recommendation [33]. Thus, overall bleeding complication rates will decrease, and the relationship of specific risk factors to bleeding complications may be somewhat altered by this reduction in dosage.

In summary, the use of thrombolytic therapy is associated with a trade-off between lysis of coronary thrombus for establishment of vessel patency and the risk of hemorrhagic complications. Because the action of fibrin-specific agents is likely to be the same at the site of the coronary thrombus and at the site of extracardiac vascular hemostatic plugs, a significant risk of bleeding will always accompany the therapeutic benefit of thrombolytic therapy. Patients with increased risk of bleeding can be identified, to some extent, by evaluation of simple clinical parameters. Our results suggest that consideration of dose adjustment may be important in women, in older patients, and in lighter patients. Little role for intensive monitoring of the degree of fibrinogenolysis was found because of the weak relationship of these factors to bleeding complications. Additional studies are needed to allow better identification of patients at increased risk of bleeding.

\section{ACKNOWLEDGMENT}

We wish to express our appreciation to Elizabeth Hall for preparation of the manuscript and lo Kerry L. Lee, M.D., Ph.D., for his careful review of the manuscript.

\section{REFERENCES}

1. Collen D: Human tissue-type plasminogen activator: from the laboratory to the bedside. Circulation 1985; 72: 18-20.

2. Collen D: Systemic thrombolytic therapy of acute myocardial infarction? Circulation 1983; 68: 462-465.

3. Sobel BE, Gross RW, Robison AK: Thrombolysis, clot selectivity, and kinetics. Circulation 1984; 70: 160-164.

4. Timmis GC, Gangadharan V, Ramon RG, et al: Hemorrhage and the products of fibrinogen digestion after intracoronary administration of streptokinase. Circulation 1984: 69: 1146-1152.

5. Tennant SN, Dixon J, Venable TC, et al: Intracoronary thrombolysis in patients with acute myocardial infarction: comparison of the efficacy of urokinase with streptokinase. Circulation 1984; 69: 756-760.

6. Burket MW, Smith MR, Walsh TE, Brewster PS, Fraker TD: Relation of effectiveness of intracoronary thrombolysis in acute myocardial infarction to systemic thrombolytic state. Am J Cardiol 1985; 56: 441-444.

7. Tendera MP, Campbell WB, Tennant SN, Ray WA: Factors influencing probability of reperfusion with intracoronary ostial infusion of thrombolytic agent in patients with acute myocardial infarction. Circulation 1985; 71: 124-185.

8. Topol EJ, Bell WR, Weisfeldt ML: Coronary thrombolysis with recombinant tis- sue-type plasminogen activator. A hematologic and pharmacologic study. Ann Intern Med 1985; 103: 837-843.

9. Collen D, Topol EJ, Tiefenbrunn AN, et al: Coronary thrombolysis with recombinant human tissue-type plasminogen activator: a prospective randomized, placebo controlled trial. Circulation 1984; 70: 1012-1017.

10. Verstraete $M$, Bleifeld W. Brower RW, et al: Double-blind randomised trial of intravenous tissue-type plasminogen activator versus placebo in acute myocardial infarction. Lancet 1985; 11: 965-969.

11. Rao AK, Pratt C, Berke A, et al: Thrombolysis in Myocardial Infarction (TIMI) Trial-Phase I: hemorrhagic manifestations and changes in plasma fibrinogen and fibrinolytic system in patients treated with recombinant tissue plasminogen activator and streptokinase. J Am Coll Cardiol 1988; 11: 1-11.

12. Lew AS, Hod $H$, Cercek $B$, et al: Mortality and morbidity rates of patients older and younger than 75 years with acute myocardial infarction treated with intravenous streptokinase. Am J Cardiol 1978; 59: 1-5.

13. Topol EJ, Califf RM, George BS, et al: A multicenter randomized trial of intravenous recombinant tissue plasminogen activator and immediate versus deferred angioplasty in acute myocardial infarction. N Engl J Med 1987; 317: 581-588.

14. Topol EJ, Califf RM, Kereiakes DS, George BS: Thrombolysis and Angioplasty in Myocardial Infarction (TAMI) Trial. J Am Coll Cardiol 1987; 10: 65B-74B.

15. Topol EJ, George BS, Kereiakes DJ, et al: Comparison of two dose regimens of intravenous tissue plasminogen activator for acute myocardial infarction. Ann $J$ Cardiol 1988; 61: 723-728.

16. Stump DC, Topol EJ, Chen AB, Hopkins A, Collen D: Monitoring of hemostasis parameters during coronary thrombolysis with recombinant tissue-type plasminogen activator. Thromb Hemostasis 1988; 59: 133-137.

17. Clauss $A$ : Gerinnungsphysiologische Schnellmethode zur Bestimmung des Fibrinogens. Acta Haematol 1957; 37: 237-246.

18. Rampling MW, Gaffney RJ: The sulphite precipitation method for fibrinogen measurement: its use on a small sample in the presence of fibrinogen degradation products. Clin Chem Acta 1963; 8: 418-424.

19. Merskey C, Lalezari $P$, Johnson AJ: A rapid, simple, sensitive method for measuring fibrinolytic split products in human serum. Proc Soc Exp Biol Med 1969; 131: $871-875$.

20. Holvoet $P$, Cleemput $H$, Collen $D$ : Assay of human tissue-type plasminogen activator ( $t$-PA) with an enzyme linked immunosorbent assay (ELISA) based on three murine monoclonal antibodies to t-PA. Thromb Haemost 1985; 54 : 684687.

21. Verheilen JH, Chang GTG, Kluff C: Evidence for the occurrence of fast acting inhibitor for tissue-type plasminogen activator in human plasma. Thromb l laemost 1984; 511: 392-395.

22. Landefeld CS, Cook EF, Hatley $M$, Weisberg $M$, Goldman L: Identification and pretiminary validation of predictors of major bleeding in hospitalized patients starting anticoagulant therapy. Am J Med 1987; 82: 703-713.

23. TIMI Study Group: The Thrombolysis in Myocardial Infarction (TIMI) Trial. N Engl J Med 1985; 312: 932-936.

24. Mueller HS, Rao AK, Forman SA, and the TIMI Investigators: Thrombolysis in myocardial infarction (TIMI): comparative studies of coronary reperfusion and systemic fibrinogenolysis with two forms of recombinant tissue-type plasminogen activator. J Am Cardiol 1987; 10: 479-490.

25. Verstraete $M$, Bernard $R$, Bory $M$, et al: Randomised trial of intravenous recombinant human tissue-type plasminogen activator versus intravenous streptokinase in acute myocardial infarction. Lancet $1985 ; \mathrm{I}: 842-847$

26. Gruppo Italiano Per Lo Studio Della Streptochinasi Nell'Infarcto Miocardio (GISSI): Effectiveness of intravenous thrombolytic treatment in acute myocardial infarction. Lancet 1986; I: 397-401.

27. The I.S.A.M. Study Group: A prospective trial of intravenous streptokinase in acute myocardial infarction (I.S.A.M.). N Engl J Med 1986; 314: 1465-1471

28. O'Neill W, Timmis $G$, Bourdillon $P$, et al: A prospective randomized clinical trial of intracoronary streptokinase versus coronary angioplasty therapy of acute myocardial infarction. N Engl J Med 1986; 314: 812-828.

29. Fung AY, Lai $P$, Juni JE, et al: Prevention of subsequent exercise-induced periinfarct ischemia by emergency coronary angioplasty in acute myocardial infarction: comparison with intracoronary streptokinase. J Am Coll Cardiol 1986; 8: 496-503.

30. Fung AY, Lai $P$, Topol EJ, et al: Value of percutaneous transluminal coronary angioplasty aftcr unsuccessful intravenous streptokinase therapy in acute myocardial infarction. Am J Cardiol 1986; 58: 686-691.

31. Stack RS, O'Connor CM, Mark DB, et al: Coronary reperfusion during acute myocardial infarction with combined coronary angioplasty and high dose intravenous streptokinase therapy. Circulation 1988; 77: 141-161.

32. Califf RM, Massey EW: Myocardial infarction and stroke in the thrombolytic cre. In: Califf RM, Mark DB, Wagner GS, cds. Acute coronary care in the thrombolytic era. Chicago: Yearbook, 1988; 539-547.

33. Braunwaid EB, Knatterud GL, Passamani ER, et al: Announcement of protocol change in Thrombolysis and Myocardial Infarction Trial (letter). J Am Coll Cardiol 1987; 9: 467. 